\title{
FATORES QUE AFETAM A ESCOLHA DA PROFISSÃO CONTÁBIL: UM ESTUDO REALIZADO COM OS ALUNOS DE UMA IES PÚBLICA DE MINAS GERAIS
}

\author{
FACTORS AFFECTING THE CHOICE OF THE ACCOUNTING PROFESSION IN \\ ACCOUNTING: A STUDY CARRIED OUT WITH THE STUDENTS OF A PUBLIC \\ UNIVERSITY IN MINAS GERAIS STATE
}

\author{
Jessica Aparecida Alves Rodriguês ${ }^{1}$ \\ Universidade Federal de Uberlândia (UFU) \\ rodriguesjessica@live.com
}

\author{
Camila Lima Bazani \\ Universidade Federal de Uberlândia (UFU) \\ camilabazani@ufu.br
}

\author{
Edvalda Araujo Leal \\ Universidade Federal de Uberlândia (UFU) \\ edvalda@ufu.br
}

\begin{abstract}
RESUMO
Esta pesquisa investigou os fatores que afetam a escolha da profissão contábil na percepção dos alunos do curso de Ciências Contábeis de uma Instituição de Ensino Superior pública do estado de Minas Gerais. Trata-se de uma pesquisa qualitativa com abordagem descritiva, tendo sido analisado três construtos: fatores psicológicos, sociais e econômicos. Os dados foram coletados por meio da aplicação de um questionário a estudantes matriculados nos quatro períodos iniciais, sendo a amostra final composta por 170 participantes. Os resultados encontrados demonstram que, quanto aos fatores psicológicos, o motivo de maior relevância consiste em ter uma autonomia de atuação na profissão contábil. Quanto aos fatores sociais, a questão de poder atuar em diferentes áreas foi a de maior destaque. Em relação aos fatores econômicos, o elemento associado a uma melhor remuneração no mercado de trabalho foi de grande influência na decisão dos estudantes pela escolha da profissão contábil.
\end{abstract}

Palavras-chave: Ciências Contábeis. Escolha Profissional. Motivação. Fatores Psicológicos, Sociais e Econômicos.

\section{ABSTRACT}

This study investigated factors affecting the choice of the accounting profession in Accounting students' perception of a public university in Minas Gerais state. It's a qualitative research with a descriptive approach and analyzed three constructs: psychological, social and economic factors. Data were collected through the application a questionnaire to students enrolled in the

\footnotetext{
${ }^{1}$ Av. João Naves de Ávila, 2121 - Sala 1F248 - Campus Santa Mônica - Uberlândia-MG. CEP: 38408-100
} 
first four periods of the course, with the final sample consisting of 170 participants. The results found demonstrate that in the psychological factors, the most relevant reason is related to having a range of activity in the accounting profession. In the social factors the matter of being able to work in different areas was the most prominent. In the economic factors the element associated to a better payment in the market had a great influence in the students' decision for choosing the accounting profession.

Keywords: Accounting. Professional Choice. Motivation. Psychological, Social and Economic factors.

\section{INTRODUÇÃO}

A formação em um curso de nível superior tem se tornado cada vez mais necessária aos que buscam sucesso no mercado de trabalho. Para Bento e Falconelli (2013), o ingresso no curso superior traz consigo desafios que permeiam as esferas social, econômica e humana. Nesse contexto, Pereira (2010) argumenta que os jovens vivem tempos conflituosos ocasionados pelas mudanças no mercado de trabalho que exigem indivíduos mais competitivos, adaptativos e competentes e, por isso, há a necessidade de orientar o aluno para a escolha certa. Assim, essa pode ser considerada uma decisão de grande responsabilidade para um jovem.

Atualmente existem inúmeras carreiras pelas quais os jovens podem optar para se inserirem no mercado de trabalho. Entretanto, muitas vezes, é essa multiplicidade de profissões que dificulta a tomada de decisão dos estudantes. Dias (2009) acredita que a escolha profissional é um fato que gera conflitos e contradições. Para a autora, estes jovens não se consideram aptos para o mercado de trabalho, haja vista que a demanda por qualificações tem se intensificado cada vez mais.

Neste cenário, Lassance (1987) afirma que a escolha profissional é uma tarefa difícil, muitas vezes acentuada por estereótipos profissionais que definem e determinam divisões e hierarquias entre etnias, sexos, gêneros e padrões socioeconômicos. Mello (2002) também argumenta que a opção por uma carreira nem sempre é algo fácil e pode tornar-se uma tortura para o jovem que precisa se posicionar diante de uma profissão. Isso ocorre porque, normalmente, a escolha é feita numa época de transformações e mudanças físicas e psíquicas, o que por si só já gera conflitos. Além disso, a sociedade, a família e os amigos cobram urgência num posicionamento para o qual nem sempre o jovem está preparado.

Miranda (2001) salienta que a escolha da profissão a ser seguida pelo jovem requer o mínimo de conhecimento a respeito do exercício da profissão. Pinheiro e Santos (2010, p. 3) ressaltam que "o grande volume de informações, as incertezas quanto ao mercado de trabalho e a concorrência para conquistar uma vaga na faculdade são fatores que afetam a procura de um emprego e aumentam a pressão sobre essas escolhas".

De acordo com Bock (2002), a necessidade da escolha cada vez mais cedo, o grande número de opções, as inúmeras mudanças e exigências do mercado de trabalho são os fatores que mais contribuem para a dificuldade e insegurança do jovem no momento de sua escolha profissional. Para Kroenke et al. (2009), a prática do dia a dia, além do conhecimento adquirido na universidade, são atributos que contribuirão na solução dos problemas quando estes jovens se tornarem profissionais.

$\mathrm{Na}$ escolha da carreira na área de contabilidade não é diferente. Desse modo, alguns estudos buscam compreender quais são os fatores mais importantes para que os alunos escolham a carreira na área. Internacionalmente, os estudos realizados por Ahmed, Alam e Alam (1997), Jackling e Calero (2007), Chen, Jones e Mcintyre (2008) e Sugahara, Boland e 
Cilloni (2008) indicaram a preocupação acadêmica em relação ao baixo nível de qualificação educacional dos estudantes na área contábil e buscaram investigar os fatores determinantes na escolha da carreira, assim como Maudlin, Crain e Mounce (2000), Ghani e Said (2009), Odia e Ogiedu (2013), Umar (2014), Alanezi et al. (2016) e Tang e Seng (2016). Nacionalmente, os estudos de Bomtempo (2005), Lacerda, Reis e Santos (2008), Pinheiro e Santos (2010), Hsiao e Casa Nova (2016), Marques, Silva e Salviano (2016) e Peleias, Nunes e Carvalho (2017), analisaram os fatores psicológicos, sociais e econômicos e/ou fatores internos e externos como determinantes da escolha profissional.

Tendo consciência da dificuldade que existe na escolha da profissão pelos jovens estudantes, a presente investigação avança na busca de conhecimento sobre os aspectos que influenciam a opção pelo curso de Ciências Contábeis. A questão que instigou a pesquisa é: Quais são os fatores que influenciam na escolha da profissão contábil? Logo, o objetivo desta pesquisa é investigar os fatores que afetam a escolha da profissão contábil na percepção dos alunos do curso de Ciências Contábeis de uma Instituição de Ensino Superior pública do estado de Minas Gerais.

Este estudo tem como base a pesquisa de Bomtempo (2005), que analisou os fatores que influenciam os alunos na escolha pelo curso de graduação em Administração. Justifica-se a utilização do questionário validado pela pesquisa de Bomtempo (2005) dado que são cursos da área de negócios e, portanto, possuem similaridades, inclusive com disciplinas em comum. Além disso, tal como ocorreu com o curso de Administração, o curso de Ciências Contábeis registrou um crescimento acentuado entre 2007 e 2012, com expansão no número de matriculados (INEP, 2014), além do crescente número de registros no Brasil pelo Conselho Federal de Contabilidade entre 2004 e 2016 (CFC, 2016).

Ainda, propõe-se o presente o estudo à medida que se nota um aumento no número de matriculados no curso de Ciências Contábeis, sendo este curso o $4^{\circ}$ maior em número de matrículas no ano de 2017 (INEP, 2018). Ademais, verifica-se que pesquisas que abrangem os fatores psicológicos, sociais e econômicos concomitantemente, especificamente para o curso de Ciências Contábeis ainda não são tão difundidas.

Entende-se, portanto, que a presente pesquisa poderá, além de contribuir com a literatura, auxiliar no esclarecimento de dúvidas e indagações sobre o perfil e a trajetória do acadêmico do curso de Ciências Contábeis, podendo propiciar uma adequada sintonia entre os diversos atores envolvidos no desenvolvimento e aperfeiçoamento de tal curso. Além disso, estudos dessa natureza podem colaborar para compreender e melhorar aspectos relativos ao ambiente acadêmico, permitindo aos docentes que desenvolvam atividades que aproximem a academia do mercado de trabalho.

\section{REFERENCIAL TEÓRICO}

\subsection{FATORES MOTIVACIONAIS QUE AFETAM A ESCOLHA PROFISSIONAL}

A motivação pode ser entendida como o ato de motivar, exposição de motivos ou causas, conjunto de fatores psicológicos, conscientes ou não, de ordem fisiológica, intelectual ou afetiva, que determina certo tipo de conduta de alguém (FERREIRA, 1988).

Para Recinella (2005), a motivação surge de fatores que estão ligados simplesmente ao que uma pessoa quer da vida, sendo os motivos pessoais intransferíveis, estando, ainda, intimamente ligados à cabeça e ao coração. Isso significa que os motivos são abstratos e só têm significado para as pessoas, visto que a motivação é algo pessoal, pois vem de dentro. Neste contexto, Lacerda, Reis e Santos (2008) argumentam que a motivação pode se tratar também 
de fatores extrínsecos como, por exemplo, a questão salarial, a ascensão profissional, o mercado de trabalho e a influência da família e de amigos.

A motivação faz parte das Teorias Comportamentais e segundo Bergamini (1997) pode assumir tanto um significado relacionado a lócus de controle interno, isto é, dentro do indivíduo, quanto ao lócus de controle externo, dependendo de situações específicas. Lieury e Fenouillet (2000) argumentam que a motivação abrange questões biológicas e psicológicas que são responsáveis por desencadear a ação. Na mesma perspectiva, Bzuneck (2004) assegura que a motivação é entendida vezes como fator psicológico, vezes como um processo, contudo, ambos levam a um mesmo resultado, que é iniciar um comportamento com vistas a um objetivo.

Para expor os fatores que afetam a motivação de uma pessoa, a Teoria das Necessidades Adquiridas de McClenlland (1961) aponta que todas as pessoas possuem três tipos de necessidades importantes: necessidade de realização, que é a busca pelo sucesso na vida pessoal ou profissional; necessidade de poder, que é quando uma pessoa busca ter influência e controle sobre a vida das pessoas; e necessidade de afiliação, que é o desejo de se relacionar com os demais e viver em um espírito mais cooperativo. Ainda segundo a Teoria de McClenlland, uma pessoa pode se tornar desmotivada para alcançar determinadas metas que foram propostas caso uma dessas necessidades não seja suprida.

Além das necessidades que compreendem a Teoria de McClenlland, Bergamini (1997) afirma que existem muitas razões que explicam uma simples ação. Grande parte desses determinantes reside no interior das pessoas, tais como, os seus traços de personalidade, suas predisposições e emoções, as suas atitudes, bem como suas crenças, dentre outros.

Ribeiro (2007) assevera que o passo primordial é assumir a postura de que a motivação é uma atitude. $\mathrm{O}$ autor explica que isso demonstra que não há como se motivar ou motivar alguém e manter a motivação em níveis compatíveis com o desempenho esperado se não houver o firme compromisso pessoal nesse sentido. $O$ autor explica ainda que as pessoas são influenciadas por emoções e que o profissional precisa compreender que, para ser bemsucedido, deverá ser um eterno estudante, como fazem os atletas, os músicos e outros profissionais conscientes.

Estudos anteriores revelaram os motivos pelos quais os estudantes são influenciados a escolher uma determinada profissão. Almeida e Buesa (2012) citam a motivação como o principal fator que influencia na escolha da profissão e, também, a sua importância na vida das pessoas. No estudo, as autoras concluíram que existe uma diversidade de interesses diferentes sobre uma mesma meta, deixando bem claro que as pessoas não fazem a mesma coisa pela mesma razão, provando isso a partir do estudo de caso realizado com a primeira turma de Contabilidade da Faculdade de Administração e Ciências Contábeis São Roque - FAC São Roque.

Soares (2002) aponta seis fatores que podem interferir na decisão de escolha de um indivíduo: (i) político; (ii) econômico; (iii) psicológico; (iv) social; (v) familiar; (vi) educacional. Segundo a autora, o primeiro refere-se às ações governamentais e políticas concernentes à educação. Os fatores econômicos são relativos ao mercado de trabalho, ao nível de empregabilidade, à informatização, às competências da profissão, entre outros. Os fatores psicológicos são aqueles intrínsecos ao indivíduo. Os sociais são alusivos à divisão da sociedade em classes sociais, sua influência no contexto familiar e à busca da ascensão social por meio do estudo. $\mathrm{O}$ fator relacionado à família corresponde ao processo de busca de realização dos projetos familiares em detrimento dos pessoais, bem como a influência desses nas decisões e construção de diferentes papéis profissionais. Por fim, os fatores educacionais são pertinentes às esferas de ensino, tanto público quanto privado. 
Abordando outros fatores influenciadores, o estudo de Florêncio, Lucena e Costa (2008) retrata as causas gerais relacionadas à tomada de decisão acerca da escolha profissional. Os resultados indicaram quatro fatores, sendo eles: 66,54\%, família; 19,6\%; outros aspectos (salário, status etc.); 8,3\%, professores e colegas; e 5,56\%, mídia. Os autores evidenciaram que os resultados obtidos são coerentes com os encontrados por Zagury (1997), o qual identificou em seu estudo que os pais ainda são a maior fonte de influência para os filhos na escolha profissional.

Assim, com o propósito de contribuir com a difusão e fortalecimento dessa literatura, além do aprimoramento do ambiente acadêmico, a presente pesquisa pretende investigar os motivos que influenciam na escolha da carreira contábil a partir do ingresso no curso de Graduação em Ciências Contábeis.

\subsection{ESCOLHA DA CARREIRA NA ÁREA CONTÁBIL}

Segundo Carvalho (2007), o termo carreira surgiu em meados do Século XIX em um ambiente predominantemente industrial e capitalista liberal, onde os valores e crenças da sociedade na época eram orientados por princípios de igualdade, liberdade e êxito individual, progresso econômico e social, pilares que viabilizavam a mobilidade social, exclusivamente dependente do esforço individual. Bastos (1997) menciona que a diferença das práticas de relação entre capital e trabalho, em comparação com o feudalismo, marcou uma nova era nas relações de trabalho, fazendo com que a compreensão e o entendimento do significado de carreira levem em consideração sua dimensão formada por um conjunto de características que variam de acordo com as ocupações e profissões.

Em síntese, Carvalho (2007) relaciona os termos acima comentados como sendo a carreira um aglomerado entre profissão e ocupação, de modo que a profissão circunscreve um conjunto de conhecimentos e habilidades. Já a ocupação agrega a dimensão da complexidade da formação e o reconhecimento social, deixando, então, que o termo carreira assuma uma dimensão de tempo envolvendo um conjunto variado de atividades que podem se alterar ou não ao longo de uma trajetória profissional. Em conclusão, Carvalho (2007) afirma que a ocupação e a profissão só se tornarão uma carreira quando inseridas em uma dimensão temporal.

No intuito de contribuir com o entendimento do termo carreira, Magalhães (2005) afirma que a carreira está integrada às questões históricas, econômicas, culturais e à duas dimensões que estão relacionadas com o seu conceito. A primeira delas é a dimensão externa, que estabelece uma ligação direta da carreira com o conceito de profissão, de maneira que esta passa a ser a história dos cargos, das responsabilidades e das funções que são atribuídas aos profissionais. Com relação à segunda dimensão, classificada como interna, a carreira é vista como uma identificação com a própria profissão, sendo percebida como vocação, de acordo com Magalhães (2005).

Para Bendassoli (2009), o conceito de carreira apresenta uma diversidade de definições, ou seja, emprego assalariado ou atividade não remunerada, pertencimento ao grupo profissional ou uma carreira solo, vocação ou ocupação. Esse autor explica que o conceito de carreira envolve a posição do indivíduo na organização ou a trajetória do indivíduo que trabalha por conta própria, alocação de recursos humanos em uma organização ou roteiro pessoal para realização dos próprios desejos. Rowe e Bastos (2010) destacam que nas estruturas organizacionais atuais são requeridos trabalhadores dotados de inteligência e flexibilidade e com competência para assumirem o controle de suas vidas, tanto nos aspectos laborais, como na carreira. 
A liberdade de escolha dos indivíduos, seja consciente ou sob influências externas, é questionada por Soares (2002). Para a autora, quando uma pessoa tem consciência daquilo que a influencia, sua seleção torna-se mais assertiva e viável. A autora considera, ainda, que as pessoas são colocadas constantemente em circunstâncias de escolha, passando por esse processo muitas vezes (da infância à vida adulta), das pequenas às mais complexas, que envolvem uma série de esferas de suas vidas, como a carreira. Além disso, a autora explica que a escolha que o indivíduo deseja fazer sugere o reconhecimento do que ele foi até o momento e, também, a definição de um estilo de vida, pois o tipo de trabalho escolhido irá ou não possibilitar a realização de suas expectativas.

Carvalho (2007) ilustra o processo de escolha da carreira ao destacar a influência dos fatores internos e externos, conforme Quadro 1.

Quadro 1 - Modelo de escolha da profissão/carreira e área de atuação

\begin{tabular}{|ll|}
\hline Fatores Externos & Fatores Internos \\
\hline Influência de pessoas significativas; & Liberdade para tomar decisões; \\
\hline Realidade de mercado; & Interesses pessoais e profissionais; \\
\hline Status social; & Habilidades; \\
\hline Remuneração; & Vocação pessoal \\
\hline Variáveis demográficas. & \\
\hline
\end{tabular}

Fonte: Carvalho (2007).

No campo da contabilidade, a literatura apresenta estudos internacionais como a pesquisa de Ahmed, Alam e Alam (1997) que investigou os fatores que influenciam os estudantes a seguir uma carreira em contabilidade, e identificaram 5 fatores: (i) disponibilidade de emprego, (ii) bons salários iniciais, (iii) bons salários em longo prazo, (iv) recompensa intrínseca, e (v) experiência com contabilidade durante o Ensino Médio. Foram testadas variáveis intrínsecas diversas (segurança no emprego, progressão na carreira, recompensas, disponibilidade de emprego, dentre outras). Os achados evidenciaram que apenas os fatores de mercado e financeiros foram relevantes para a decisão dos estudantes seguirem a carreira em contabilidade.

Jackling e Calero (2007) pesquisaram as percepções dos estudos em contabilidade de estudantes de comércio do primeiro ano na Austrália, tendo como objetivo abordar os fatores importantes para determinar se esses alunos pretendem se tornar contadores. O estudo utilizouse de um modelo de regressão logística incorporando fatores demográficos e acadêmicos, bem como as percepções dos alunos sobre o trabalho dos contadores, para prever a intenção de se tornar um contador. Os resultados mostraram que a percepção de importância das habilidades genéricas, o interesse intrínseco na área disciplinar e a satisfação com o curso foram relevantes na decisão em seguir a carreira contábil.

O estudo de Chen, Jones e Mcintyre (2008) objetivou analisar as percepções de estudantes de negócios de uma universidade dos Estados Unidos quanto aos benefícios e custos de se tornar um profissional de Ciências Contábeis, identificando se o contato com a contabilidade no ensino médio e a qualidade de sua experiência são fatores que influenciaram na opção pela carreira contábil. Os resultados apontaram que o contato prévio com a contabilidade no ensino médio pode ser percebido como uma vantagem, porém a experiência não foi fator influenciador. Por fim, fatores de mercado são percebidos como relevantes, enquanto fatores intrínsecos não se mostraram como influenciadores.

Com o objetivo de verificar os fatores que influenciam a escolha dos estudantes pelo curso de contabilidade, Sugahara, Boland e Cilloni (2008) realizaram um estudo no Egito. A pesquisa foi motivada pela preocupação com o declínio da qualificação educacional dos 
contadores. A amostra do estudo foi composta de 273 alunos e os resultados indicaram as variáveis relacionadas à escolha da carreira, sendo: percepções da profissão contábil, habilidades pessoais e temas propostos para a educação contábil.

Maudlin, Crain e Mounce (2000), ao evidenciarem a dificuldade em atrair estudantes para a área contábil, descobriram que os educadores e a faculdade desempenham um importante papel na escolha da carreira dos contadores. Ghani e Said (2009) investigaram, com o uso de questionários, se há diferença na escolha da carreira contábil por alunos malaios e chineses. Para os dois grupos, os fatores interesse pessoal e, também, a influência dos familiares foram os elementos que mais se destacaram na escolha pelo curso.

O estudo de Odia e Ogiedu (2013) examinou os fatores que afetam a escolha da contabilidade na carreira de estudantes em três universidades nigerianas, contando com uma amostra de 300 alunos. Os autores constataram que são diversos os fatores que influenciam a decisão dos estudantes pelo curso de Ciências Contábeis, contudo, têm-se os fatores pessoais e de trabalho, como o interesse e a motivação dos alunos no assunto, perspectivas de alto salário e o desempenho no ensino médio, como os fatores mais influentes da escolha da contabilidade dos alunos. Umar (2014) também investigou os fatores que influenciam a escolha da carreira na contabilidade entre estudantes universitários nigerianos. $\mathrm{O}$ autor encontrou que o desejo próprio, bem como as perspectivas futuras são os fatores mais influentes.

A pesquisa de Alanezi et al. (2016) buscou explorar os fatores que influenciam a decisão dos alunos pela área contábil. Os autores constataram que oportunidades de carreira, prestígio e assunto interessante têm uma influência significativa na decisão dos alunos de optar pela contabilidade. Já Tang e Seng (2016), tendo como base a demanda crescente por contabilistas qualificados e profissionais no Camboja, objetivaram determinar os fatores que influenciam os estudantes a escolher a contabilidade. Eles verificaram que orientação, fator de característica pessoal e idade possuem uma relação positiva e significativa com a escolha pelos alunos, e, além disso, tem uma relação negativa, mas significativa com a expectativa da carreira.

No que tange às pesquisas nacionais, o estudo realizado por Bomtempo (2005), trabalho base utilizado para a presente pesquisa, analisou os fatores que influenciam os alunos na escolha pelo curso de graduação em Administração e como esses fatores se relacionam. Para alcançar os resultados, o autor promoveu um agrupamento dos fatores de escolha, segmentando-os em três categorias: fatores sociais, fatores psicológicos e fatores econômicos.

Para relacionar os fatores com a escolha dos estudantes, Bomtempo (2005) utilizou três modelos, denominando como primeiro modelo o $\mathrm{S}$, que se caracteriza por apresentar o fator social como antecedente na escolha da carreira. O autor afirma que, nessa hipótese, os elementos da cultura e sociedade, como classe social, educação, família, religião, dentre outros, seriam os elementos iniciais no processo de escolha pelo curso de Administração. O segundo modelo foi denominado pelo autor como $\mathrm{P}$, definindo que o indivíduo seria levado a fazer uma opção pela força dos aspectos psicológicos, destacados por Bomtempo (2005) como as concepções individuais, o lado pessoal ou a premissa da liberdade das pessoas na condução de seus destinos. Já o terceiro modelo, denominado pelo autor como E, refere-se aos aspectos econômicos enquanto condicionantes da escolha dos alunos, como políticas salariais, demanda profissional e crescimento populacional.

A coleta de dados no estudo de Bomtempo (2005) foi realizada junto a 258 estudantes de cursos de graduação em Administração em quatro Instituições de Ensino Superior da rede privada localizadas na cidade de São Paulo. Na análise, o autor utilizou a técnica estatística Modelagem de Equações Estruturais e, de acordo com os critérios estabelecidos, os resultados 
indicaram maior aderência aos dados amostrais pelo modelo que estabelece fatores sociais como antecedentes no processo de escolha vocacional.

O estudo de natureza quantitativa de Pinheiro e Santos (2010), que utilizou como base o estudo de Bomtempo (2005), objetivou responder a seguinte questão de pesquisa: "É possível identificar a ordem de precedência dos fatores na escolha pelo curso superior em Ciências Contábeis na região pesquisada?". Para tanto, os autores também utilizaram a Modelagem de Equações Estruturais buscando identificar os motivos que influenciam o aluno na escolha do curso. Foi aplicado um questionário a uma amostra não probabilística de 579 alunos de Ciências Contábeis em doze Instituições de Ensino Superior da capital e Grande São Paulo. Utilizou-se de uma escala Likert com 32 indicadores baseados nos construtos: econômico, psicológico e social. Os resultados demonstraram que: quanto ao construto econômico, destacaram-se a "melhor remuneração" e "complementa minha ocupação atual" como as principais razões para a escolha; em relação ao construto social, têm-se como "ter uma profissão de prestígio" e que "permite ascender mais rapidamente a um cargo diretivo"; já referente ao construto psicológico, os estudantes consideram como sendo a "contribuição para o desenvolvimento pessoal" ou que "traz mais prazer que as outras profissões".

Lacerda, Reis e Santos (2008) buscaram identificar e analisar os fatores extrínsecos e intrínsecos que motivam e influenciam a escolha e a permanência dos alunos no curso de Ciências Contábeis da Unimontes. Para cumprir o objetivo, aplicou-se no ambiente acadêmico a Teoria de Dois Fatores de Herzberg, a qual versa sobre os fatores extrínsecos e os intrínsecos. A estratégia metodológica utilizada foi o levantamento descritivo, com uma amostra intencional e um questionário estruturado para coletar os dados juntos aos alunos, com questões abertas e fechadas. Os testes de média realizados indicam que no que diz respeito aos fatores intrínsecos, novos conhecimentos e agregar experiências são os principais motivos para a escolha do curso. Já entre os fatores extrínsecos, a melhoria salarial e a ascensão profissional são os principais motivos. Além disso, outros fatores também se revelaram importantes para a permanência do discente no curso, sendo a interação entre alunos e professores e o desafio de aprendizagem dentre os fatores intrínsecos, e entre os fatores extrínsecos, a possibilidade de ingresso no mercado de trabalho.

Já Hsiao e Casa Nova (2016), ao compreenderem as características de indivíduos da nova geração que estão entrando no mercado de trabalho, a Geração Y, buscaram identificar quais fatores influenciam tal geração ao escolher a carreira em Ciências Contábeis. Para tanto, os autores utilizaram questionário, adaptado a partir de entrevista em grupo focal, tendo uma amostra total de 665 indivíduos, sendo alunos do ensino médio que participaram de uma edição da Feira de Carreiras da USP. Os participantes da pesquisa foram divididos em cinco categorias, com base nas áreas de conhecimento identificadas pela Coordenação de Aperfeiçoamento de Pessoal de Nível Superior (Capes): a) Ciências Sociais Aplicadas, onde a contabilidade está inserida; b) Ciências Exatas; c) Ciências Biológicas; d) Ciências Humanas; e) Outras. A análise foi realizada considerando a área Ciências Sociais Aplicadas, pois os resultados da pesquisa mostraram que poucos indivíduos considerariam a carreira em Ciências Contábeis.

Os resultados da pesquisa mostraram que determinados fatores intrínsecos da profissão - criatividade, autonomia, ambiente desafiador e dinâmico - exerceram influência no processo de escolha da carreira. Por outro lado, embora seja também fator intrínseco, os fatores sociais não influenciaram tal processo. Além disso, os autores observaram que há menor influência da família no processo de escolha da carreira, sendo justificada, por exemplo, pelos novos tipos de estrutura familiar. Por fim, o questionário aplicado apontou que a tradição se apresenta como menos relevante para os indivíduos que seguem carreira em contabilidade, mas que eles são 
bastante abertos a novas experiências e à liberdade para agir e tomar decisões, além de buscarem realização e felicidade.

Marques, Silva e Salviano (2016) analisaram dados de 252 questionários aplicados a estudantes de uma das maiores universidades privadas do país objetivando identificar e analisar os fatores determinantes na escolha pelo curso de Ciências Contábeis. Os resultados demonstraram que os fatores possíveis de maior influência para essa escolha são: atuar em diversas áreas; imagem e reputação da instituição; curso que evolui com o mercado; profissão que proporciona autonomia de atuação; amplia a cultura e desenvolvimento geral e; profissão que possui grande oferta de emprego.

Tal como o estudo apresentado imediatamente anterior, Peleias, Nunes e Carvalho (2017), analisaram questionários aplicados a alunos com o intuito de identificar e analisar os fatores que influenciaram a escolha de estudantes pelo ingresso no curso de graduação em Ciências Contábeis. Foram avaliados 123 questionários provenientes de alunos matriculados em três universidades particulares da cidade de São Paulo. Os resultados também demonstram que os fatores mais influentes estão associados à perspectiva de carreira.

\section{ASPECTOS METODOLÓGICOS}

A presente pesquisa se classifica quanto à abordagem do problema como qualitativa, com aprofundamento das variáveis que possam ser consideradas determinantes na análise e na reflexão do fenômeno pesquisado (MINAYO, 2004). Quanto aos objetivos, como descritiva, pois, como dito por Andrade (2002), a pesquisa descritiva preocupa-se em observar os fatos, fazer o registro, a análise, a classificação e a interpretação, sem que a haja a interferência do pesquisador. Segundo Gil (1999), a intenção da pesquisa descritiva é traçar características de determinada população ou fenômeno ou o estabelecimento de relações entre as variáveis.

Quanto aos procedimentos para a coleta de dados, utilizou-se o levantamento (survey) por meio da aplicação de um questionário. Segundo Gil (1999, p. 70), as pesquisas que se utilizam do levantamento "se caracterizam pela interrogação direta das pessoas, cujo comportamento se deseja conhecer". De acordo com Marconi e Lakatos (2011, p. 86) "o questionário é um instrumento de coleta de dados constituído por uma série ordenada de perguntas, que devem ser respondidas por escrito e sem a presença do entrevistador". Por meio de questionários é possível obter informações que envolvem medir atitudes, opiniões, comportamento da vida dos indivíduos, e outras questões.

$\mathrm{O}$ instrumento de pesquisa (questionário) foi dividido em três partes: a primeira objetivou coletar dados sobre a caracterização dos alunos, a segunda questionou informações sobre alternativas analisadas no momento da escolha do curso e continuidade dos estudos, e, na terceira foram apresentadas as questões sobre a escolha do curso. Para essa terceira parte, utilizou-se o modelo proposto e testado por Bomtempo (2005) para a escolha da carreira. Importante ressaltar, que o modelo (escala) foi validado pelo autor indicado. O questionário contou com assertivas divididas em três blocos: fatores psicológicos, sociais e econômicos. Ainda, utilizou-se a escala de Likert com cinco pontos, iniciando por discordo totalmente até concordo totalmente.

No Quadro 2, apresenta-se um esquema de construção dos indicadores com a relação entre as assertivas do questionário e os fatores sociais, psicológicos e econômicos propostos por Bomtempo (2005). 
Quadro 2 - Fatores propostos para as assertivas do instrumento de coleta de dados

\begin{tabular}{|c|c|}
\hline Assertivas: EU ESCOLHI CIÊNCIAS CONTÁBEIS PORQUE... & Fatores \\
\hline ...é um curso de mais fácil ingresso (menos concorrido). & \multirow{12}{*}{ Psicológicos } \\
\hline ...imaginei que o curso me traria maior prazer que os demais. & \\
\hline ...recebi pressão da empresa onde trabalho/trabalhei. & \\
\hline ... a imagem da instituição é boa (credibilidade, qualidade, etc.) & \\
\hline ...é uma profissão que contribui para o desenvolvimento pessoal. & \\
\hline ....amplia minha cultura geral e meu desenvolvimento intelectual. & \\
\hline ...tenho habilidades típicas da profissão (autogerenciamento, etc.) & \\
\hline ...é uma carreira que proporciona autonomia de atuação. & \\
\hline ...é um curso com menor dificuldade de compreensão. & \\
\hline ...nenhum outro curso me interessou. & \\
\hline ...obtive boas recomendações de amigos, gerente, professores, etc. & \\
\hline ...tive sugestões familiares. & \\
\hline ...é uma profissão de prestígio. & \multirow{10}{*}{ Sociais } \\
\hline ...pretendo conduzir a empresa da família. & \\
\hline ...proporciona ascensão profissional rápida. & \\
\hline ....a instituição fica em um local conveniente (acesso, segurança). & \\
\hline ...é um curso muito procurado atualmente. & \\
\hline ...me permite alcançar, de forma rápida, um cargo gerencial. & \\
\hline ...temos tradição familiar nessa carreira. & \\
\hline ...é um curso que se mantém atualizado com o mercado. & \\
\hline ...é uma profissão sólida, que dá estabilidade no emprego. & \\
\hline ...a profissão me permite atuar em diferentes áreas. & \\
\hline ...era a minha única opção visto a nota do ENEM ou vestibular. & \multirow{10}{*}{ Econômicos } \\
\hline ...a profissão proporciona melhor remuneração no mercado. & \\
\hline ...a profissão oferece maiores ofertas de emprego. & \\
\hline ...é uma profissão compatível com a minha condição social. & \\
\hline ...tem duração compatível com a minha situação financeira. & \\
\hline ...o mercado de trabalho não está saturado para essa profissão. & \\
\hline ...me identifico com os profissionais da área. & \\
\hline ...obtive custeio da empresa onde trabalho/trabalhei. & \\
\hline ...completa a minha ocupação atual. & \\
\hline .... instituição oferecia facilidades financeiras (bolsas, descontos). & \\
\hline
\end{tabular}

Fonte: Bomtempo (2005).

Antes da aplicação do questionário ao público-alvo da pesquisa, realizou-se um préteste do instrumento com 12 alunos do curso de Ciências Contábeis matriculados no $9^{\circ}$ período, cujo objetivo foi verificar a compreensibilidade das questões, tendo sido dadas algumas sugestões, as quais foram acatadas.

A população do estudo abrange os alunos matriculados nos períodos iniciais $\left(1^{\circ}\right.$ ao $\left.4^{\circ}\right)$ em ambos os turnos, integral e noturno, do curso de Ciências Contábeis de uma IES Pública de Minas Gerais. Segundo informações da coordenação de curso da instituição em estudo, eram 400 alunos matriculados nesses períodos.

A amostra final do estudo compreendeu 170 participantes que se prontificaram a responder o questionário, ou seja, $42,5 \%$ da população. A aplicação do questionário foi realizada em sala de aula, de forma presencial, com a autorização da coordenação de curso e dos professores das disciplinas.

Para apurar os resultados, utilizou-se a análise descritiva dos dados, pela qual se propôs a examinar e discutir com profundidade os fatores que influenciam na escolha da carreira da área contábil. Foram observados o perfil dos participantes, a motivação pela escolha do curso 
de Ciências Contábeis e os fatores que influenciam a escolha do curso, abrangendo os três construtos: psicológicos, sociais e econômicos.

\section{ANÁLISE E DISCUSSÃO DOS RESULTADOS}

\subsection{CARACTERIZAÇÃO DOS RESPONDENTES}

Nessa etapa da análise de resultados, procedeu-se à exploração do perfil dos respondentes. Para cada característica apurada, como, por exemplo, período, turno, sexo, idade, foram observadas as frequências nas diferentes categorias. A Tabela 1 ilustra os resultados e permite uma identificação da heterogeneidade amostral.

Tabela 1 - Caracterização do perfil dos respondentes

\begin{tabular}{|c|c|c|c|c|c|c|c|}
\hline \multicolumn{4}{|c|}{ Período em curso } & \multicolumn{2}{|l|}{ Turno } & \multicolumn{2}{|l|}{ Sexo } \\
\hline $1^{\mathrm{o}}$ & $2^{\circ}$ & $3^{\circ}$ & $4^{\circ}$ & Integral & Noturno & Masculino & Feminino \\
\hline $17,6 \%$ & $29,4 \%$ & $25,9 \%$ & $27,1 \%$ & $58,2 \%$ & $41,8 \%$ & $43,5 \%$ & $56,5 \%$ \\
\hline \multicolumn{5}{|l|}{ Idade } & \multicolumn{3}{|c|}{ Estado Civil } \\
\hline & $56,5 \%$ & \multicolumn{2}{|c|}{ Solteiro } & $85,3 \%$ \\
\hline \multicolumn{4}{|c|}{ De 21 a 29 anos } & $32,9 \%$ & \multicolumn{2}{|l|}{ Casado } & $12,4 \%$ \\
\hline \multicolumn{4}{|c|}{ Acima de 30 anos } & $10,6 \%$ & \multicolumn{2}{|l|}{ Outro } & $2,3 \%$ \\
\hline \multicolumn{5}{|c|}{ Escolaridade do Pai } & \multicolumn{3}{|c|}{ Escolaridade da Mãe } \\
\hline \multicolumn{4}{|c|}{ Superior completo } & $21,2 \%$ & \multicolumn{2}{|c|}{ Superior completo } & $26,5 \%$ \\
\hline \multicolumn{4}{|c|}{ Superior incompleto } & $5,9 \%$ & \multicolumn{2}{|c|}{ Superior incompleto } & $10,0 \%$ \\
\hline \multicolumn{4}{|c|}{ Ensino médio completo } & $32,4 \%$ & \multicolumn{2}{|c|}{ Ensino médio completo } & $30,6 \%$ \\
\hline \multicolumn{4}{|c|}{ Ensino médio incompleto } & $10,6 \%$ & \multicolumn{2}{|c|}{ Ensino médio incompleto } & $12,9 \%$ \\
\hline \multicolumn{4}{|c|}{ Fundamental completo } & $11,8 \%$ & \multicolumn{2}{|c|}{ Fundamental completo } & $6,5 \%$ \\
\hline \multicolumn{4}{|c|}{ Fundamental incompleto } & $17,6 \%$ & \multicolumn{2}{|c|}{ Fundamental incompleto } & $12,9 \%$ \\
\hline \multicolumn{4}{|c|}{ Analfabeto } & $0,5 \%$ & \multicolumn{2}{|c|}{ Analfabeto } & $0,6 \%$ \\
\hline \multicolumn{5}{|c|}{ Emprego Atual } & \multicolumn{3}{|c|}{ Renda da Família } \\
\hline \multicolumn{4}{|c|}{ Registro em carteira } & $27,1 \%$ & \multicolumn{2}{|c|}{ Até $\mathrm{R} \$ 880,00$} & $2,9 \%$ \\
\hline \multicolumn{4}{|c|}{ Sem vínculo empregatício } & $7,6 \%$ & \multicolumn{2}{|c|}{ De $\mathrm{R} \$ 881,00$ até $\mathrm{R} \$ 1.400,00$} & $6,5 \%$ \\
\hline \multicolumn{4}{|c|}{ Profissional liberal } & $2,9 \%$ & De $\mathrm{R} \$ 1.4$ & até $\mathrm{R} \$ 2.800,00$ & $20,0 \%$ \\
\hline Estagiá & & & & $12,4 \%$ & De 2.801 & $\mathrm{R} \$ 5.600,00$ & $44,7 \%$ \\
\hline Não tra & alho & & & $42,4 \%$ & De 5.601, & $\mathrm{R} \$ 11.200,00$ & $18,8 \%$ \\
\hline Outras & rmas & & & $7,6 \%$ & Acima de & $.201,00$ & $7,1 \%$ \\
\hline
\end{tabular}

Fonte: Dados da Pesquisa.

Percebeu-se que, do total de 170 respondentes, a maior parte, $29,4 \%$, apresentou-se no segundo período regular do curso de Ciências Contábeis com turno integral de estudo $(58,2 \%)$. Verificou-se ainda que a maioria dos respondentes é do sexo feminino $(56,5 \%)$, com idade de, no máximo, 20 anos $(56,5 \%)$.

Percebe-se que os estudantes do curso de Ciências Contábeis pertencem à geração Y, que nasceram a partir de 1978, compreendem outro conceito de trabalho, baseado em um acordo psicológico diferente do que foi estabelecido pelos seus antecessores (VELOSO et al., 2016). Segundo os autores, estes jovens consideram o trabalho mais do que uma fonte econômica, e sim como uma satisfação e aprendizado, alterando o entendimento de carreira.

Com relação ao grau de instrução da família, a maioria dos respondentes tem pais com ensino médio completo, sendo $32,4 \%$ para a categoria pai e $30,6 \%$ para a categoria mãe. Quanto à ocupação, identificou-se que $57,6 \%$ da amostra de estudantes têm alguma forma de trabalho e que sua renda, adicionada à da sua família, é, na maior parte da amostra $(44,7 \%)$, na faixa de $\mathrm{R} \$ 2.801,00$ até $\mathrm{R} \$ 5.600,00$. 


\subsection{ANÁLISE DESCRITIVA DAS VARIÁVEIS EM ESTUDO}

Já em relação às questões, foi possível identificar como os respondentes optaram por ingressar no curso de Ciências Contábeis a partir de variáveis como informações sobre o curso e a área no mercado de trabalho, recursos financeiros, experiência profissional, dentre outros. A Tabela 2 evidencia os resultados encontrados na percepção dos estudantes.

Tabela 2 - Variáveis em estudo

\begin{tabular}{lll}
\hline Variáveis & Sim \% & Não \% \\
\hline Este é o primeiro curso superior que você está fazendo? & 69,4 & 30,6 \\
Antes deste curso, você participou de processos seletivos para outra graduação? & 68,2 & 31,8 \\
Você tinha informações suficientes sobre o curso quando fez a escolha? & 50,0 & 50,0 \\
Sua decisão, no momento da escolha, foi segura? & 61,2 & 38,2 \\
Se você tivesse recursos (financeiros, tempo) teria escolhido outro curso? & 41,2 & 58,2 \\
Quando ingressou no curso, você já possuía experiência profissional? & 31,8 & 68,2 \\
Se fosse hoje, você optaria novamente pelo curso? & 81,8 & 19,4 \\
Os ensinamentos das disciplinas estão sendo proveitosos para o seu dia-a-dia? & 52,4 & 18,2 \\
Após a conclusão deste curso, você pretende iniciar uma nova graduação? & 81,8 & 47,6 \\
Pretende fazer um curso de pós-graduação (especialização, mestrado...)? & 18,2 \\
\hline
\end{tabular}
Fonte: Dados da Pesquisa.

Verificou-se que a maioria dos respondentes, 69,4\%, está cursando a primeira graduação. Apesar desse detalhe, 68,2\% dos alunos não optaram pelo curso de Ciências Contábeis no primeiro processo seletivo para ingressar no ensino superior. Essa posição mostra relação com os resultados obtidos por Bomtempo (2005) quanto ao curso de Administração, os quais evidenciam $91,1 \%$ para a questão da primeira graduação e $53,9 \%$, referente à opção do curso.

Com relação às informações do curso, 50\% dos respondentes de uma amostra de 170 alunos afirmaram que detinham detalhes suficientes sobre a graduação em Ciências Contábeis. Esse resultado, ao ser comparado com o de Bomtempo (2005), que encontrou um percentual de $38,8 \%$ para uma amostra de 258 respondentes, pode ilustrar que alunos do curso de Contabilidade possuem maiores informações para escolha do curso quando comparados aos alunos do curso de Administração. E talvez, por considerarem ter informações suficientes, $61,2 \%$ dos alunos da contabilidade responderam de forma positiva quando da decisão feita de forma segura.

Percebeu-se também que, na visão dos respondentes $(58,2 \%)$, os fatores relacionados a tempo e recursos financeiros afetariam de forma negativa a escolha pelo curso de Ciências Contábeis, mas, apesar desse detalhe, identificou-se que a maioria dos alunos $(80,6 \%)$ optaria novamente pela graduação em contabilidade, afirmando $(81,6 \%)$ que o conteúdo das disciplinas é proveitoso no dia a dia. Ainda, a maioria dos respondentes $(52,4 \%)$ tem a pretensão de iniciar uma nova graduação após a titulação de Bacharel em Ciências Contábeis ou ainda um curso de especialização, sendo $81,8 \%$ dos estudantes para essa última opção. Notou-se também que a parcela maior da amostra em análise $(68,2 \%)$ não tinha experiência profissional até o momento da escolha do curso.

\subsection{POSICIONAMENTO SOBRE OS FATORES DE INFLUÊNCIA}

Nesta etapa da pesquisa, as variáveis investigadas no estudo foram divididas em assertivas relacionadas a três construtos de fatores que podem influenciar na escolha do curso de Ciências Contábeis, sendo eles: Psicológicos, Sociais e Econômicos. Conforme mencionado na metodologia, adotou-se uma escala Likert de cinco pontos para medir a intensidade de 
concordância com as assertivas, sendo: DT (Discordo Totalmente), DP (Discordo Parcialmente), I (Indiferente), CP (Concordo Parcialmente) e CT (Concordo Totalmente). A análise foi realizada de acordo com a frequência nas respostas obtidas a partir do questionário aplicado.

A Tabela 3 apresenta os resultados de acordo com o percentual de respondentes que marcaram cada nível da escala para os fatores psicológicos.

Tabela 3 - Fatores Psicológicos

\begin{tabular}{l|l|l|l|l|l}
\hline Fatores Psicológicos & DT & DP & I & CP & CT \\
\hline 1. É um curso de mais fácil ingresso (menos concorrido). & 14,7 & 19,4 & 31,8 & 23,5 & 10,6 \\
2. Imaginei que o curso me traria maior prazer que os demais. & 5,3 & 5,9 & 22,9 & 47,6 & 18,3 \\
3. Recebi pressão da empresa onde trabalho/trabalhei. & 84,7 & 2,9 & 9,4 & 1,8 & 1,2 \\
4. A imagem da instituição é boa (credibilidade, qualidade, etc.). & 1,2 & 7,1 & 12,4 & 41,2 & 38,1 \\
5. É uma profissão que contribui para o desenvolvimento pessoal. & 1,8 & 8,2 & 17,6 & 48,8 & 23,6 \\
6. Amplia minha cultura geral e meu desenvolvimento intelectual. & 3,5 & 4,7 & 19,4 & 44,1 & 28,3 \\
7. Tenho habilidades típicas da profissão (autogerenciamento, etc.). & 5,9 & 7,6 & 25,3 & 44,7 & 16,5 \\
8. É uma carreira que proporciona autonomia de atuação. & 2,9 & 5,3 & 12,4 & 37,6 & 41,8 \\
9. É um curso com menor dificuldade de compreensão. & 25,9 & 18,8 & 35,3 & 17,1 & 2,9 \\
10. Nenhum outro curso me interessou. & 32,4 & 21,2 & 20,0 & 19,3 & 7,1 \\
11. Obtive boas recomendações de amigos, gerente, professores, etc. & 5,2 & 7,1 & 21,2 & 41,8 & 24,7 \\
12. Tive sugestões familiares. & 21,2 & 8,8 & 21,1 & 32,4 & 16,5 \\
\hline
\end{tabular}

Fonte: Dados da pesquisa

Identificou-se que, das 12 assertivas relacionadas aos fatores psicológicos, quatro delas (itens 4, 5, 6 e 8) se destacaram de forma positiva, com elevado percentual de concordância. Para os itens 4 e 8, que versam sobre a boa imagem e credibilidade da instituição de ensino e sobre a autonomia de atuação na carreira, respectivamente, o índice de concordância entre os respondentes é de quase $80,0 \%$. Já para os itens 5 e 6 , relativos ao desenvolvimento pessoal e desenvolvimento intelectual que o curso de contabilidade pode proporcionar, respectivamente, a aprovação é de $72,4 \%$.

Tais resultados corroboram com os achados de Pinheiro e Santos (2010) e Marques, Silva e Salviano (2016), que encontraram que o fator desenvolvimento pessoal obteve destaque como um influenciador no processo de escolha vocacional. Além disso, o fator autonomia de atuação também foi confirmado por Hsiao e Casa Nova (2016) como relevante nesse processo, que destacaram que a liberdade para agir e para tomada de decisões tem forte influência. Já os resultados concernentes especificamente ao item 4, que condiz com a boa imagem da instituição, vão ao encontro dos achados de Maudlin, Crain e Mounce (2000) e Marques, Silva e Salviano (2016), que verificaram resultados significativos quanto ao papel da faculdade nesta escolha, incluindo a imagem e reputação desta instituição.

Já o item 7, que diz respeito às habilidades pessoais, obteve $61,2 \%$ de concordância, corroborando com os resultados dos estudos de Sugahara, Boland e Cilloni (2008) e Marques, Silva e Salviano (2016), que identificaram as habilidades pessoais como um fator que influencia a escolha da carreira de contabilidade. Os achados de Jackling e Calero (2007) mostram que habilidades genéricas para profissão são relevantes no processo de decisão da carreira profissional. Em contrapartida, esse resultado não confirma o achado de Chen, Jones e Mcintyre (2008), de que fatores intrínsecos não influenciam.

Ainda em relação aos fatores psicológicos, a maioria dos respondentes $(87,6 \%)$ afirmou que a opção por contabilidade não se deve ao fato de existir uma pressão por parte da empresa em que presta/prestou serviços (item 3), visto que essa mesma maioria não tinha experiência profissional no momento da escolha. Nessa mesma linha, o estudo de Chen, Jones e Mcintyre 
(2008) já apresentava que a experiência não influencia na escolha da profissão. Por outro lado, agregar experiências consiste em um fator significativo para a escolha dos estudantes, conforme evidenciaram Lacerda, Reis e Santos (2008).

Quanto ao item 2, relacionado ao interesse próprio em acreditar no prazer trazido pela profissão, este pode ser considerado como fator influenciador por apresentar $65,9 \%$ de aprovação, e dessa forma, corrobora também com outro achado de Pinheiro e Santos (2010), em que os estudantes consideraram que a contabilidade é uma profissão que traz maior prazer que outras. Ghani e Said (2009), Odia e Ogiedu (2013) e Umar (2014) também constataram que o interesse pessoal é fator de elevada influência.

Destaca-se, ainda, que o item 12, concernente às sugestões familiares para a escolha profissional, não se apresentou tão relevante, assim como o resultado da pesquisa de Hsiao e Casa Nova (2016). Entretanto, não corrobora com os achados de Ghani e Said (2009) que verificaram haver influência familiar para a decisão de escolha do curso.

$\mathrm{Na}$ Tabela 4 são apresentados os resultados de acordo com o percentual de respondentes que marcaram cada nível da escala relacionados aos fatores sociais, tendo sido analisados dez itens.

Tabela 4 - Fatores Sociais

\begin{tabular}{l|l|l|l|l|l}
\hline Fatores Sociais & DT & DP & I & CP & CT \\
\hline 1. É uma profissão de prestígio. & 2,3 & 5,9 & 15,9 & 51,8 & 24,1 \\
2. Pretendo conduzir a empresa da família. & 60,0 & 3,5 & 20,0 & 8,9 & 7,6 \\
3. Proporciona ascensão profissional rápida. & 4,7 & 12,9 & 30,0 & 40,0 & 12,4 \\
4. A instituição fica em um local conveniente (acesso, segurança). & 9,4 & 10,6 & 29,4 & 30,6 & 20,0 \\
5. É um curso muito procurado atualmente. & 5,3 & 11,2 & 35,9 & 37,6 & 10,0 \\
6. Me permite alcançar, de forma rápida, um cargo gerencial. & 8,9 & 15,3 & 28,2 & 40,0 & 7,6 \\
7. Temos tradição familiar nessa carreira. & 51,2 & 9,4 & 17,6 & 12,4 & 9,4 \\
8. É um curso que se mantém atualizado com o mercado. & 2,4 & 2,9 & 12,4 & 51,2 & 31,1 \\
9. É uma profissão sólida, que dá estabilidade no emprego. & 2,9 & 11,3 & 19,4 & 43,5 & 22,9 \\
10. A profissão me permite atuar em diferentes áreas. & 1,2 & 2,4 & 8,2 & 38,8 & 49,4 \\
\hline
\end{tabular}

Fonte: Dados da Pesquisa.

Verifica-se que, das 10 assertivas relacionadas aos fatores sociais, os respondentes desatacaram de forma positiva, com $75,9 \%$, a questão associada ao prestígio que a profissão contábil pode proporcionar (item 1). Esse resultado confirma o achado de Pinheiro e Santos (2010) em que os respondentes consideraram a contabilidade uma profissão de prestígio e isso era fator influenciador em sua decisão vocacional, assim como o resultado apresentado por Alanezi et al. (2016).

Percebeu-se também que 82,3\% dos alunos concordaram que o curso de Ciências Contábeis mantém atualizadas as informações em relação ao mercado (item 8), além de se tratar de uma carreira que permite atuar em diversas áreas, conforme 88,2\% dos estudantes relataram (item 10). A existência desse ambiente dinâmico foi apresentada no estudo de Hsiao e Casa Nova (2016) como um aspecto positivo na escolha pela carreira contábil. Alanezi et al. (2016) e Marques, Silva e Salviano (2016) também já haviam constatado que as oportunidades de carreira com a possibilidade de atuação em diferentes áreas são fatores influenciadores nesta escolha.

Fatores sociais referentes à tradição (item 7) e condução de uma empresa familiar (item 2 ), do ponto de vista de mais de $60 \%$ dos respondentes, foram elementos que não motivaram a escolha profissional apesar de 48,9\% dos alunos afirmarem que houve uma influência da família no momento da escolha profissional, conforme indicado nos fatores psicológicos (Tabela 3). 
Esses achados também corroboram com os resultados de Hsiao e Casa Nova (2016), que apontaram pouca relevância da tradição e da influência familiar.

Verificou-se que a expectativa de rápida ascensão profissional (item 3) obteve a concordância entre os respondentes de $62,4 \%$, o que confirma os achados de Lacerda, Reis e Santos (2008), de que o fator extrínseco ascensão profissional é influenciador e com os de Pinheiro e Santos (2010), que teve o motivo social de ascender mais rapidamente a um cargo diretivo como destaque.

Por fim, verifica-se que o alcance, de forma rápida, de um cargo gerencial (item 6) não pode ser considerado tão significativo nesse processo de escolha profissional, pois a concordância entre os respondentes ficou em torno de 50\%. Contudo, Umar (2014), Tang e Seng (2016) e Peleias, Nunes e Carvalho (2017) constaram que as perspectivas futuras de modo geral relacionadas à carreira são fatores influenciadores.

A análise descritiva dos fatores econômicos ligados à escolha da carreira é evidenciada na Tabela 5, onde é apresentado o percentual de respondentes que marcaram cada nível da escala.

Tabela 5 - Fatores Econômicos

\begin{tabular}{l|l|l|l|l|l}
\hline Fatores Econômicos & DT & DP & I & CP & CT \\
\hline 1. Era a minha única opção visto a nota do ENEM ou vestibular. & 58,2 & 15,3 & 13,5 & 10,6 & 2,4 \\
2. A profissão proporciona melhor remuneração no mercado. & 3,5 & 11,8 & 18,8 & 55,3 & 10,6 \\
3. A profissão oferece maiores ofertas de emprego. & 1,2 & 4,1 & 14,1 & 50,6 & 30,0 \\
4. É uma profissão compatível com a minha condição social. & 11,2 & 7,1 & 40,0 & 33,5 & 8,2 \\
5. Tem duração compatível com a minha situação financeira. & 9,4 & 13,5 & 51,2 & 20,6 & 5,3 \\
6. O mercado de trabalho não está saturado para essa profissão. & 8,2 & 11,2 & 20,0 & 40,0 & 20,6 \\
7. Me identifico com os profissionais da área. & 5,9 & 11,2 & 26,5 & 41,8 & 14,7 \\
8. Obtive custeio da empresa onde trabalho/trabalhei. & 82,4 & 2,4 & 12,9 & 2,3 & 0,0 \\
9. Completa a minha ocupação atual. & 19,4 & 10,6 & 32,9 & 20,0 & 17,1 \\
10. A instituição oferecia facilidades financeiras (bolsas, & 52,4 & 4,7 & 29,3 & 7,1 & 6,5 \\
descontos). & & & & & \\
\hline
\end{tabular}

Fonte: Dados da Pesquisa.

Nesse terceiro construto, das dez assertivas relacionadas aos fatores econômicos, duas se destacaram de forma positiva, visto que $80,6 \%$ dos estudantes concordaram que a profissão contábil tem um amplo mercado de trabalho por ter maiores ofertas de emprego (item 3), inclusive, em diversas áreas, confirmando o achado de Marques, Silva e Salviano (2016), além de 65,9\% dos alunos afirmarem que a carreira proporciona uma melhor remuneração (item 2), elemento que pode estar ligado à questão de a carreira viabilizar ascensão profissional rápida, que é uma questão do construto social (item 3). A relevância do item 2 confirma o achado de Lacerda, Reis e Santos (2008), de que o fator extrínseco melhoria salarial é um dos principais motivos para a escolha do curso de Ciências Contábeis e corrobora com o resultado de Odia e Ogiedu (2013) de que a perspectiva de alto salário é um fator que influencia a decisão de escolha. Ahmed, Alam e Alam (1997), embora tenham analisado estudantes de uma geração diferente da presente pesquisa e possivelmente com uma realidade econômica também diferente, igualmente identificaram que os fatores de mercado e financeiros são relevantes para a decisão dos estudantes seguirem a carreira em contabilidade.

De forma negativa também se destacaram dois elementos relacionados aos fatores econômicos, sendo uma discordância de $84,8 \%$ dos respondentes referente à obtenção de custeio por parte da empresa onde trabalha/trabalhou (item 8) e 73,5\% dos estudantes em relação às opções em decorrência das notas do ENEM ou vestibular (item 1). E, embora o fator classe social esteja situado no Modelo S da pesquisa de Bomtempo (2005), sendo, portanto, 
considerado um fator de influência, na presente pesquisa, a condição social é abordada no construto fatores econômicos (item 4) e não se mostrou com forte influência.

Por fim, ressalta-se que ao contrário do estudo de Bomtempo (2005), que utilizou a Modelagem de Equações Estruturais (SEM) para indicar os antecedentes sociais na escolha vocacional, encontrando o Modelo S como o mais aderente, esta pesquisa auferiu resultados por meio de uma combinação dos três construtos em análise. Isso permite ilustrar que tanto os fatores psicológicos, como os sociais e econômicos, indicam elementos que influenciam na escolha da carreira pelos jovens, em maior ou menor grau, todos sendo analisados na presente pesquisa.

\section{CONSIDERAÇÕES FINAIS}

Neste estudo, buscou-se investigar os fatores que afetam a escolha da profissão contábil na percepção dos alunos do curso de Ciências Contábeis de uma Instituição de Ensino Superior pública do estado de Minas Gerais por meio da análise descritiva de três construtos identificados na literatura: fatores psicológicos, fatores sociais e fatores econômicos.

Os resultados auferidos possibilitaram identificar os principais motivos reconhecidos pelos alunos, para cada um dos fatores, tanto psicológicos, como sociais e econômicos, procurando os elementos de maior relevância no seu processo de escolha do curso. Ao organizar a relação entre os três elementos com percentuais em destaque, para cada item de cada construto, percebe-se que, em relação aos fatores psicológicos, o motivo de maior relevância está relacionado a ter uma autonomia de atuação na profissão contábil, seguido da boa imagem associada à instituição. Quanto aos fatores sociais, a questão de poder atuar em diferentes áreas foi a de maior destaque e, em relação aos fatores econômicos, o elemento associado a maiores ofertas de empregos foi de grande influência na decisão dos estudantes.

Percebe-se que os itens com maior concordância, mesmo sendo de construtos diferentes, apresentam certa relação, ou seja, os estudantes de Ciências Contábeis, no momento da decisão por uma profissão, buscam a autonomia para atuar em diversas áreas, associando, para isso, a imagem da instituição e a expectativa de maiores ofertas de emprego, além de uma remuneração que seja compensatória.

Resgatando as contribuições da presente pesquisa, além de colaborar na difusão e fortalecimento da literatura, os resultados permitem o esclarecimento de dúvidas e indagações sobre o perfil dos alunos que ingressaram no curso de Ciências Contábeis, compreendendo os fatores que o levaram a decidir por tal carreira, podendo propiciar uma adequada sintonia entre os diversos atores envolvidos no desenvolvimento e aperfeiçoamento do curso.

De acordo com os resultados colhidos, pode-se dizer que este estudo pode contribuir com a formação acadêmica dos estudantes à medida que, a partir destes achados, os docentes da IES pesquisada podem analisar o perfil dos estudantes, principalmente no que tange à escolha da carreira e, assim, buscarem métodos de ensino que aproximem a academia do mercado de trabalho. Isso se mostra particularmente relevante quando identificamos os achados de Jackling e Calero (2007), que mostraram que além do interesse na área, a satisfação com o curso é fator relevante para os estudantes na decisão de seguir na carreira contábil.

Ademais, compreender os fatores que motivam e as expectativas dos alunos ao buscarem a carreira contábil pode permitir o desenvolvimento de atrativos tanto para ingresso quanto para a manutenção desses estudantes no curso.

Ressalta-se que há limitações na generalização dos resultados, dado que a pesquisa foi realizada no âmbito de apenas uma IES. Sendo assim, indica-se, para futuras pesquisas, a replicação do estudo em outras instituições de ensino, que podem ser públicas e/ou privadas, e, 
também, a comparação dos fatores da escolha da carreira em diferentes cursos de graduação. Além disso, sugere-se que pesquisas sejam efetuadas no intuito de aprofundar resultados e compreender outras questões que podem ser fomentadas a partir dos resultados aqui expostos, por exemplo, quais os motivos para que a maioria dos alunos não optem pelo curso de Ciências Contábeis no primeiro processo seletivo para ingressar no ensino superior?

Destaca-se, ainda, a necessidade de estudos nacionais de modo a contribuir para melhores comparativos e análises dos resultados, haja vista que a comparação com estudos internacionais se torna limitada em virtude da existência de contextos distintos entre os países no que tange aos quesitos econômicos, culturais e sociais.

\section{REFERÊNCIAS}

ALANEZI, F. S.; ALFRAIH, M. M., HADDAD, A. E.; ALTAHER, N. A. Factors Influencing Students' Choice of Accounting as a Major: Further Evidence from Kuwait. Global Review of Accounting and Finance, v. 7, n. 1, p. 165-177, 2016. https://doi.org/10.21102/graf.2016.03.71.12

ALMEIDA, F. F.; BUESA, N. Y. A motivação dos alunos e profissionais das Ciências Contábeis na escolha dessa profissão: um estudo de caso com os alunos da primeira turma de contabilidade da FAC São Roque. Revista Eletrônica Gestão e Negócios, v. 3, n. 1, 2012.

ANDRADE, M. M. Como preparar trabalhos para cursos de pós-graduação: noções práticas. 5. ed. São Paulo: Atlas, 2002.

AHMED, K.; ALAM, K. F.; ALAM, M. An empirical study of factors affecting accounting student's career choice in New Zealand. Accounting Education, v. 6, n. 4, p. 325-335, 1997. https://doi.org/10.1080/096392897331398

BASTOS, A. V. B. A escolha e o comprometimento com a carreira: um estudo entre profissionais e estudantes de Administração. Revista de Administração, v. 32, n. 3, p. 28-39, 1997.

BENDASSOLLI, P. F. Recomposição da relação sujeito-trabalho nos modelos emergentes de carreira. Revista de Administração de Empresas, v. 49, n. 4, p. 387-400, 2009.

https://doi.org/10.1590/S0034-75902009000400003

BENTO, A. R.; FALCONELLI, E. F. A dificuldade do jovem na escolha de um curso superior. In: CONGRESSO NACIONAL DE EDUCAÇÃO EDUCERE, 11., 2013, Curitiba. Anais... Curitiba: PUC-PR, 2013. Disponível em: http://educere.bruc.com.br/arquivo/pdf2013/7893_4729.pdf. Acesso em: 12 jan. 2018.

BERGAMINI, C. W. Motivação nas organizações. 4. ed. São Paulo: Atlas, 1997.

BOCK, S. D. Orientação profissional: a abordagem sócio-histórica. 2. ed. São Paulo: Cortez, 2002. 
BOMTEMPO, M. S. Análise dos fatores de influência na escolha pelo curso de graduação em Administração: um estudo sobre as relações de causalidade através da Modelagem de Equações Estruturais. 2005. Dissertação (Mestrado em Administração de Empresas) - Centro Universitário Álvares Penteado, São Paulo, 2005.

BZUNECK, J. A. A motivação do aluno: aspectos introdutórios. Em: E. Boruchovitch e J. A. Bzuneck (Orgs.) A motivação do aluno, 3. ed, p. 9-36. Petrópolis: Vozes, 2004.

CARVALHO, T. A. T. A escolha e o comprometimento com a profissão/carreira: um estudo entre psicólogos. 2007. Dissertação (Mestrado em Psicologia) - Universidade Federal da Bahia, Salvador, 2007.

CHEN, C., JONES, K. T.; MCINTYRE, D. D. Analyzing the Factors Relevant to Students' Estimations of the Benefits and Costs of Pursuing an Accounting Career. Accounting Education, v. 17, n. 3, p. 313-326, 2008. https://doi.org/10.1080/09639280701788703

CONSELHO FEDERAL DE CONTABILIDADE - CFC. Quantos somos. Disponível em: http://cfc.org.br/registro/quantos-somos-2/. Acesso em: 13 jan. 2018.

DIAS, M. S. L. Sentidos do trabalho e sua relação com o projeto de vida de universitários. 2009. Tese (Doutorado em Psicologia) - Universidade Federal de Santa Catarina, Florianópolis, 2009.

FERREIRA, A. B. H. Dicionário Aurélio Básico da Língua Portuguesa. Rio de Janeiro: Nova Fronteira, 1988.

FLORÊNCIO, H. J. C.; LUCENA, R. M.; COSTA, E. C. T. Dificuldades dos jovens na escolha de uma profissão: revelações de ingressantes no ensino superior em diferentes áreas do agreste pernambucano. 2008. Disponível em:

www.unimep.br/phpg/inscricao/enic/.../hugojosedecarvalhoflorencio_trab323_v1.doc. Acesso em: 20 mar. 2016.

GHANI, E. K.; SAID, J. A Comparative Study on Malay and Chinese Accounting Students' Perceptions on Accounting Career. Canadian Social Science, v. 5, n. 3, p. 1-13, 2009.

GIL, A. C. Métodos e técnicas de pesquisa social. 5. ed. São Paulo: Atlas, 1999.

HSIAO, J.; CASANOVA, S. P. C. Abordagem Geracional dos Fatores que Influenciam a Escolha de Carreira em Contabilidade. Revista Contabilidade \& Finanças - USP, v. 27, n. 72, p. 393-407, 2016.

INSTITUTO NACIONAL DE ESTUDOS E PESQUISAS EDUCACIONAIS ANÍSIO TEIXEIRA - INEP. Censo da Educação Superior. Disponível em: http://portal.inep.gov.br/web/guest/educacao-superior. Acesso em: 13 jan. 2018.

INSTITUTO NACIONAL DE ESTUDOS E PESQUISAS EDUCACIONAIS ANÍSIO TEIXEIRA - INEP. Censo da Educação Superior 2017. Disponível em: http://portal.mec.gov.br/docman/setembro-2018-pdf/97041-apresentac-a-o-censo-superior-u- 
ltimo/file. Acesso em: 21 ago. 2020.

KROENKE, A.; CARDOSO, R. S.; DOMINGUES, M. J. C. S.; HEIN, N. Fatores de atratividade para os estudantes de graduação em Ciências Contábeis na escolha da instituição de ensino. In: SEMINÁRIOS EM ADMINISTRAÇÃO FEA-USP, 12., 2009, São Paulo.

Anais... São Paulo: FEA.USP, 2009. Disponível em:

http://www.ead.fea.usp.br/semead/12semead/resultado/. Acesso em: 10 nov. 2015.

LACERDA, J. R.; REIS, S. M.; SANTOS, N. A. Os fatores extrínsecos e intrínsecos que motivam os alunos na escolha e permanência no curso de Ciências Contábeis: um estudo da percepção dos discentes numa universidade pública. Enfoque: Reflexão Contábil, v. 27, n. 1, p. 67-81, 2008.

LASSANCE, M. C. P. A profissionalização da mulher: um estudo da identidade profissional em adultas jovens em profissões tradicionalmente masculinas e tradicionalmente femininas. 1987. Dissertação (Mestrado em Educação) - Pontifícia Universidade Católica do Rio Grande do Sul, Porto Alegre, 1987.

LIEURY, A.; FENOUILLET, F. Motivação e aproveitamento escolar. Tradução de Y. M. C. T. Silva. São Paulo: Loyola, 2000.

MAGALHÃES, O. M. Personalidades vocacionais e desenvolvimento na vida adulta: Generatividade e carreira profissional. 2005. Tese (Doutorado em Psicologia) - Universidade Federal do Rio Grande do Sul, Porto Alegre, 2005.

MAUDLIN, S.; CRAIN, J. L.; MOUNCE, P. H. The Accounting Principles Instructor's influence on Students Desicion to Major in Accounting. Journal of Education for Business, v. 75, n. 2, p. 142-148, 2000.

MARCONI, M. A.; LAKATOS, E. M. Técnicas de pesquisa: planejamento e execução de pesquisas, amostragens e técnicas de pesquisas, elaboração, análise e interpretação de dados. 7 ed. São Paulo: Atlas, 2008.

MARQUES, V. A.; SILVA, C. E. S.; SALVIANO, R. A. G. Fatores determinantes da escolha do curso de ciências contábeis: uma análise a partir das teorias da motivação. Revista de Contabilidade da UFBA, v. 10, n. 3, p. 176-197, 2016. https://doi.org/10.9771/rcufba.v10i3.17767

MELLO, F. A. F. O desafio da escolha profissional. São Paulo: Papirus, 2002.

McCLELLAND, D. C. The achieving society. Princeton, New Jersey: Van Nostrand, 1961.

MINAYO, M. C. S. Pesquisa social: teoria, métodos e criatividade. 23. ed. Petrópolis, RJ: Vozes, 2004.

MIRANDA, N. A. A escolha do curso e as expectativas profissionais em relação ao mercado de trabalho, dos alunos do ensino superior noturno de Administração de 
Empresas em instituições particulares. 2001. Dissertação (Mestrado em Administração de Empresas) - Fundação e Escola de Comércio Álvares Penteado, São Paulo, 2001.

ODIA, J. O.; OGIEDU, K. O. Factors Affecting the Study of Accounting in Nigerian Universities. Journal of Educational and Social Research, v. 3, n. 3, p. 89-96, 2013. https://doi.org/10.5901/jesr.2013.v4n3p89

PELEIAS, I. R.; NUNES, C. A.; CARVALHO, R. F. Fatores determinantes na escolha do curso de Ciências Contábeis por estudantes de Instituições de Ensino Superior particulares na cidade de São Paulo. Revista GUAL, v. 10, n. 3, p. 39-58, 2017.

http://dx.doi.org/10.5007/1983-4535.2017v10n3p39

PEREIRA, C. M. G. A escolha profissional do adolescente frente às demandas familiares e ao mercado de trabalho atual. 2010. Disponível em: Portal da Eduvale $<$ http://www.eduvale.br/colegio/imprimir.php?id_editoria=\&id=528>. Acesso em: $01 \mathrm{dez}$. 2015.

PINHEIRO, R. G.; SANTOS, M. R. Fatores de escolha pelo curso de Ciências Contábeis uma pesquisa com os graduandos na Capital e Grande São Paulo. In: SEMINÁRIOS EM ADMINISTRAÇÃO FEA-USP, 13., 2010, São Paulo. Anais... São Paulo: FEA.USP, 2010. Disponível em: http://sistema.semead.com.br/13semead/resultado/trabalhosPDF/153.pdf . Acesso em: 10 nov. 2015.

RECINELLA, R. O que é motivação. 2005. Disponível em: http://www.rrecinella.com.br/artigo.asp?id=82. Acesso em: 12 nov. 2015.

RIBEIRO, R. V. Motivação é atitude. 2007. Disponível em: http://www.motivacaoeresultados.com.br. Acesso em: 12 nov. 2015.

ROWE, D. E. O.; BASTOS, A. V. B. Vínculos com a carreira e produção acadêmica: comparando docentes de IES públicas e privadas. Revista de Administração

Contemporânea, v. 14, n. 6, p. 1011-1030, 2010. http://dx.doi.org/10.1590/S1415$\underline{65552010000700003}$

SOARES, D. H. P. A escolha profissional: Do jovem ao adulto. São Paulo: Summus, 2002.

SUGAHARA, S.; BOLAND, G.; CILLONI, A. Factors influencing students' choice of an accounting major in Australia. Accounting Education: An International Journal, v. 17, Suppl 1, p. 37-54, 2008. https://doi.org/10.1080/09639280802009199

TANG, L. C.; SENG, C. Factors influence students' choice of accounting major in Cambodian universities. Accounting Education, v. 24, n. 2, p. 231-251, 2016. https://doi.org/10.1108/ARA-04-2014-0049

UMAR, I. Factors Influencing Students' Career Choice in Accounting: The Case of Yobe State University. Research Journal of Finance and Accounting, v. 5, n. 17, p. 59-62, 2014. 
VELOSO, E. F. R.; DUTRA, J.S.; NAKATA, L. E. Percepção sobre carreiras inteligentes: diferenças entre as gerações Y, X e baby boomers. REGE - Revista de Gestão, v. 23, n. 2, p. 88-98, 2016.

ZAGURY, T. O adolescente e a vida profissional. In: ZAGURY, T. O adolescente por ele mesmo: orientação para pais e educadores. Rio de Janeiro: Record, 1997. 